\title{
Effects of energy source in milk replacer on glucose metabolism of neonatal dairy calves
}

\author{
A. C. Welboren, ${ }^{1} \odot$ B. Hatew, ${ }^{2} \odot$ O. López-Campos, ${ }^{3} \oplus$ J. P. Cant, ${ }^{1} \odot$ L. N. Leal, ${ }^{4} \odot$ J. Martín-Tereso, ${ }^{4} \odot$ \\ and M. A. Steele $e^{1,2 *}$ \\ ${ }^{1}$ Department of Animal Biosciences, University of Guelph, Guelph, ON Canada, N1G 2W1 \\ ${ }^{2}$ Department of Agricultural, Food and Nutritional Science, University of Alberta, Edmonton, AB Canada, T6G 2P5 \\ ${ }^{3}$ Lacombe Research and Development Centre, Agriculture and Agri-Food Canada, Lacombe, AB Canada, T4L 1V7 \\ ${ }^{4}$ Trouw Nutrition Research and Development, PO Box 299, 3800 AG, Amersfoort, the Netherlands
}

\section{ABSTRACT}

Milk replacers (MR) formulated to contain more lactose than whole milk could potentially reduce insulin sensitivity in dairy calves. This study evaluated how partially replacing lactose in MR with fat on a weight/ weight basis affects glucose-insulin kinetics in neonatal dairy calves fed high quantities of MR. Thirty-four Holstein bull calves were blocked by dam parity $(1.6 \pm 0.3)$ and randomly assigned to 1 of 2 treatments $(\mathrm{n}=17)$ : a high-lactose MR (HL; $46.1 \%$ lactose, $18.0 \%$ crude fat, and $23.9 \%$ crude protein on a dry matter basis) or a high fat MR (HF; $39.9 \%$ lactose, $24.6 \%$ crude fat, and $24.0 \%$ crude protein on a dry matter basis). Calves were individually housed and fed pooled colostrum at $1.5 \mathrm{~h}$ and $12 \mathrm{~h}$ postnatal at 18 and $9 \%$ of metabolic body weight $\left(\mathrm{BW}^{0.75}\right)$, respectively. From 24 h postnatal until the end of the study (d 7), calves were transitioned to MR (prepared at $150 \mathrm{~g} / \mathrm{L}$ ) at $18 \%$ of $\mathrm{BW}^{0.75}$ twice daily at 0700 and $1900 \mathrm{~h}$. On d 4, an insulin-modified intravenous glucose tolerance test was conducted $8 \mathrm{~h}$ after the morning meal by intravenous infusion of glucose $\left(0.54 \mathrm{~g} / \mathrm{kg}\right.$ of $\mathrm{BW}^{0.75}$, min 0$)$ and insulin $(3.9 \mu \mathrm{g} / \mathrm{kg}$ of $\mathrm{BW}^{0.75}$, min 20). During postprandial sampling on d 6 , abomasal emptying was assessed by dosing acetaminophen $\left(0.13 \mathrm{~g} / \mathrm{kg}\right.$ of $\left.\mathrm{BW}^{0.75}\right)$ with MR and measuring its appearance within plasma. Sequential blood samples were collected and analyzed for plasma glucose, insulin, and acetaminophen concentrations. Calves were killed on d 7 and liver and pancreatic tissues were collected for histomorphological analysis. Partially replacing lactose in MR with fat increased body weight gain (679.6 vs. $462.0 \pm 69.68 \mathrm{~g} / \mathrm{d}$ ) and gain:metabolizable energy

Received August 3, 2020.

Accepted December 3, 2020.

*Corresponding author: masteele@uoguelph.ca intake (186.6 vs. $120.5 \pm 20.21 \mathrm{~g}$ of body weight/ Mcal) compared with feeding HL MR. Furthermore, abomasal emptying rate was reduced in calves fed HF MR. Calculated variables based on postprandial glucose and insulin concentrations, such as maximum concentration or area under the curve, were or tended to be lower in HF than in HL calves. Postprandial insulin sensitivity tended to be reduced in HL compared with $\mathrm{HF}$, although insulin sensitivity estimated from the insulin-modified intravenous glucose tolerance test was not different. Calves fed HF MR showed enhanced glucose-stimulated insulin secretion. In conclusion, partially replacing lactose in MR with fat resulted in smaller fluctuations in postprandial glucose and insulin concentrations and tended to increase postprandial but not fasting insulin sensitivity in neonatal dairy calves. Key words: lactose, fat, body composition, glucose homeostasis, insulin sensitivity

\section{INTRODUCTION}

Approximately $50 \%$ of all calves on US dairy farms receive milk replacer (MR) or a combination of MR and whole milk (Urie et al., 2018). Recently, calf research has focused on feeding elevated planes of milk or MR (>8 vs. $4 \mathrm{~L} / \mathrm{d}$; MacPherson et al., 2016) to improve preweaning growth performance (Khan et al., 2011); however, this practice is often implemented without considering the dietary macronutrient composition. Relative to whole milk, MR generally contains more lactose (approximately 43 vs. $38 \%$ on a DM basis) and less fat (21 vs. $28 \%$ on a DM basis; Lee et al., 2009; Pantophlet et al., 2016b; Amado et al., 2019). This is a consequence of economic restrictions that drive formulations with higher levels of protein and fat (Hof, 1980), the use of lactose-rich by-products from cheese manufacturing, and the attempt to minimize body fat deposition in growing Holstein heifers (Tikofsky et al., 2001). High lactose consumption may negatively 
affect glucose homeostasis, resulting in hyperglycemia, hyperinsulinemia, and glucosuria (Vicari et al., 2008; Pantophlet et al., 2016a). Eventually, insulin resistance may develop, as observed in milk-fed calves that received a $42 \%$ versus $29 \%$ lactose MR from wk 5 to 16 of age (Hugi et al., 1997). However, it is unclear whether the development of insulin resistance begins as early as the neonatal phase when high-lactose MR feeding commences.

Elevated feeding rates combined with a high-lactose MR will likely exacerbate any negative metabolic effects of excessive lactose consumption. A previous study by MacPherson et al. (2016) demonstrated the feasibility of feeding $8 \mathrm{~L}$ as opposed to $4 \mathrm{~L}$ of high-lactose $(45 \%$ lactose, $18 \%$ crude fat, and $24 \% \mathrm{CP}$ ) MR in 2 meals per day from wk 1 to 8 of life, resulting in negligible effects on insulin sensitivity based on data collected during an intravenous glucose tolerance test. In an attempt to reduce lactose content of MR, Pantophlet et al. (2016b) investigated partial replacement of lactose with glucose, fructose, or glycerol. In response to replacing one third of dietary lactose with glucose, fructose, or glycerol, insulin sensitivity in 97-d-old Holstein-Friesian bull calves was unaffected when $>10 \mathrm{~L}$ of MR $(47.8 \%$ lactose, $20.9 \%$ crude fat, and $20.5 \% \mathrm{CP}$ on a DM basis) per day was fed for 8 wk (Pantophlet et al., 2016b). The authors ascribe the lack of differences to the low insulin sensitivity at the start of the study and suggest that it is necessary to test the effects of a high-lactose $\mathrm{MR}$ in younger calves, as calves may be more sensitive to insulin at this time. Interestingly, postprandial plasma glucose and insulin concentrations and urinary excretion of glucose were increased in control (only lactose) and glucose calves compared with fructose and glycerol calves (Pantophlet et al., 2016b). The increase in urinary excretion of glucose suggests an imbalance in glucose homeostasis and an inefficient use of the nutrients consumed by the calf. Hence, it is relevant to understand the metabolic implications of feeding a high-lactose MR to calves early in life.

Previous studies evaluated how MR composition influences insulin sensitivity after the first week of life. In the current study, calves were enrolled immediately at birth to focus on the first week of life, during which calves transition from colostrum to milk and undergo major metabolic adaptations. We hypothesized that the excess available glucose from high-lactose MR will decrease insulin sensitivity and that a high-lactose MR will result in faster abomasal emptying. Our objective was to evaluate how partially replacing lactose in MR formulations with fat affects glucose-insulin kinetics during an insulin-modified intravenous glucose tolerance test (IM-IVGTT) and postprandial sampling in calves during their first week of life.

\section{MATERIALS AND METHODS}

The study was conducted at the Dairy Research and Technology Centre of the University of Alberta (Edmonton, AB, Canada) from September 2017 to April 2018. Animal procedures complied with the guidelines of the Canadian Council on Animal Care (CCAC, 1993) and were approved by the Animal Care and Use Committee of the University of Alberta (AUP00002418).

\section{Animals, Housing, and Treatments}

Thirty-four Holstein bull calves with an average birth BW of $43.2 \pm 0.81 \mathrm{~kg}$ were separated from the dam approximately $15 \mathrm{~min}$ after birth, weighed using an electronic scale (Digi-Star SW300, Digi-Star LLC, Fort Atkinson, WI $)$, and moved to a pen $(122 \times 183$ $\mathrm{cm}$; width $\times$ length) that was bedded with shavings and straw. Calves were dried and stimulated with clean towels for approximately $10 \mathrm{~min}$. At 1.5 and $12 \mathrm{~h}$ after birth, calves were bottle-fed pooled fresh colostrum (2.8\% lactose, $4.5 \%$ crude fat, and $12.6 \% \mathrm{CP} ; 63.9 \mathrm{~g}$ of IgG/L; Saskatoon Colostrum Company Ltd., Saskatoon, SK, Canada) at 18.1 and $9.1 \%$ of their metabolic BW $\left(\mathbf{B W}^{0.75}\right)$, respectively. Before feeding, colostrum was thawed and warmed to a temperature of $39^{\circ} \mathrm{C}$ using a water bath. If more than $25 \%$ of a colostrum meal remained, the remainder was drenched using an esophageal tube feeder. At $24 \mathrm{~h}$ after birth, blood was sampled via jugular venipuncture using serum vacutainers (Becton, Dickinson and Co., Franklin Lakes, NJ) and centrifuged at $3,000 \times g$ at $4^{\circ} \mathrm{C}$ for $20 \mathrm{~min}$. Supernatant was transferred into 1.5 - $\mathrm{mL}$ microcentrifuge tubes and frozen at $-20^{\circ} \mathrm{C}$ until analysis of serum IgG by radial immunodiffusion analysis (Saskatoon Colostrum Company quality assurance laboratory, Saskatoon, SK, Canada).

In a randomized complete block design, calves were blocked by dam parity and randomly assigned to 1 of 2 treatments $(\mathrm{n}=17)$ : a high-lactose MR $(\mathbf{H L} ; 46.1 \%$ lactose, $18.0 \%$ crude fat, and $23.9 \% \mathrm{CP}$ on a DM basis) or a high-fat MR (HF; $39.9 \%$ lactose, $24.6 \%$ crude fat, and $24.0 \% \mathrm{CP}$ on a DM basis; Sloten B.V., Trouw Nutrition, Deventer, the Netherlands). Ingredients and nutrient composition of the MR (analyzed by Masterlab, Trouw Nutrition, Boxmeer, the Netherlands) are presented in Table 1. The MR was prepared at 150 $\mathrm{g} / \mathrm{L}$ and bottle-fed at $18.1 \%$ of $\mathrm{BW}^{0.75}$. The assigned MR was fed $24 \mathrm{~h}$ after birth; thereafter, calves were adjusted to being fed twice daily at 0700 and $1900 \mathrm{~h}$. On $\mathrm{d} 4$, calves were reweighed before the morning meal and meal size was adjusted accordingly. Intake and refusal of MR was recorded for each meal. At all times, fresh water was available ad libitum from plastic buckets and 
Table 1. Ingredients and nutrient composition of the milk replacers ${ }^{1}$ used

\begin{tabular}{lcc}
\hline Variable & $\begin{array}{c}\text { High } \\
\text { lactose }\end{array}$ & $\begin{array}{c}\text { High } \\
\text { fat }\end{array}$ \\
\hline Ingredient (\%) & & \\
Skim milk powder & 29.5 & 29.5 \\
Palm and coconut oil mixture (2:1) & 16.7 & 22.6 \\
Whey products & 48.4 & 42.1 \\
Hydrolyzed wheat protein & 4.0 & 4.1 \\
Premix and others & 1.5 & 1.7 \\
Nutrient (\% of DM unless otherwise noted) & 97.5 & 97.5 \\
DM (\%) & 46.1 & 39.9 \\
Lactose & 18.0 & 24.6 \\
Crude fat & 23.9 & 24.0 \\
CP & 7.9 & 7.7 \\
Crude ash & 4.23 & 4.49 \\
ME (Mcal/kg of DM) &
\end{tabular}

${ }^{1}$ Sloten B.V., Trouw Nutrition (Deventer, the Netherlands).

intake was recorded daily. Calves were exposed to daylight and artificial light from 0600 to $1930 \mathrm{~h}$.

\section{IM-IVGTT}

On $\mathrm{d} 4$, a catheter $(16 \mathrm{G} \times 2$ in., Terumo IV Catheter Surflash, Tokyo, Japan) was inserted into the jugular vein $2 \mathrm{~h}$ after the morning meal and kept in place for 3 d. Heparinized saline $(20 \mathrm{IU} / \mathrm{mL}$; Fresenius Kabi, Bad Homburg, Germany) was used to flush the catheter line. On d 4, an IM-IVGTT was conducted $8 \mathrm{~h}$ after the morning meal. Glucose was dosed at $0.54 \mathrm{~g} / \mathrm{kg}$ of $\mathrm{BW}^{0.75}$ by infusing a $50 \%$ dextrose solution (DMVét, Western Drug Distribution Center, Edmonton, AB, Canada) via the jugular catheter over $60 \mathrm{~s}$, followed 20 min later by an infusion of bovine insulin (Hybri-Max, Millipore Sigma, Oakville, ON, Canada) at $3.9 \mu \mathrm{g} /$ $\mathrm{kg}$ of $\mathrm{BW}^{0.75}$. Sequential blood samples were collected before and after glucose infusion in a lithium heparin Vacutainer (Becton, Dickinson and Co.). Immediately after sampling, a competitive serine protease inhibitor (Aprotonin, Sigma-A1153, Millipore-Sigma) was added to blood at $5 \mu \mathrm{g} / \mathrm{mL}$. Blood was centrifuged at 3,000 $\times g$ at $4^{\circ} \mathrm{C}$ for $20 \mathrm{~min}$ and supernatant was transferred into $1.5-\mathrm{mL}$ microcentrifuge tubes and frozen at $-20^{\circ} \mathrm{C}$ until analysis of glucose and insulin concentrations.

\section{Postprandial Abomasal Emptying and Glucose and Insulin Concentrations}

Postprandial abomasal emptying and plasma glucose and insulin curves were determined on d 6 . Acetaminophen was added to the morning MR meal at $0.13 \mathrm{~g} /$ $\mathrm{kg}$ of $\mathrm{BW}^{0.75}$ and its appearance in plasma was used as an indicator of abomasal emptying (Schaer et al., 2005; MacPherson et al., 2016). Plasma was analyzed for concentrations of acetaminophen [Paracetamol (ac- etaminophen) Assay Kit-K8002; Cambridge Life Sciences Ltd., Cambridgeshire, UK] and insulin (Mercodia Bovine Insulin ELISA; Mercodia, Uppsala, Sweden) as described by MacPherson et al. (2016). Plasma glucose was determined using an enzymatic assay with peroxidase glucose oxidase and dianisidine dihydrochloride (Sigma-Aldrich, St. Louis, MO). Inter- and intra-assay coefficients of variation for plasma acetaminophen, insulin, and glucose were 0.9 and $1.3 \%, 4.7$ and $4.6 \%$, and 3.3 and $0.9 \%$, respectively.

\section{Postmortem Analysis}

Calves were killed $3 \mathrm{~h}$ after the morning meal on d 7 to collect the liver and pancreas. Pentobarbital (Euthanyl, Vetoquinol, Lavaltrie, QC, Canada) was infused intravenously at $0.125 \mathrm{~mL} / \mathrm{kg}$ of BW to achieve a surgical plane of anesthesia, after which the calf was exsanguinated. The pancreas and liver were weighed, and subsamples collected from the tail of the pancreas and the center of the right lobe of the liver were fixed for a minimum of $24 \mathrm{~h}$ in $10 \%$ buffered formalin solution (4\% formaldehyde; Fisher Scientific, Hampton, $\mathrm{NH}$ ) and snap frozen in liquid nitrogen, respectively. Then, the carcass was split at the spine and the right carcass half was stored at $-20^{\circ} \mathrm{C}$ until analysis. The fixed pancreatic tissue was processed (VIP 6, Somagen, Edmonton, AB, Canada) and embedded in paraffin (Tissue Tek, Sakura, Torrance, CA), and, subsequently, sections of $5 \mu \mathrm{m}$ were processed onto glass slides (2 sections per slide; Leica RM2255, Leica Biosystems, Buffalo Grove, IL) and stained with a hematoxylin and eosin stain (Leica ST5020, Leica Biosystems) by the Animal Health Laboratory histotechnology laboratory (University of Guelph, Guelph, ON, Canada). Images were captured using a Leica ICC50W microscope at 100× magnification (Leica Microsystems, Wetzlar, Germany). Measurements were performed using ImageJ 1.46r software (National Institutes of Health, Bethesda, MD). The size and cell count of 10 islets of Langerhans (approximately 4 images) per calf were determined to evaluate pancreatic endocrine function. Liver glycogen content was determined using a fluorometric assay (glycogen assay kit, Cayman Chemical, Ann Arbor, MI; Mann et al., 2018). Approximately $125 \mathrm{mg}$ of frozen tissue was homogenized in $1 \mathrm{~mL}$ of assay buffer and diluted 300-fold using the assay buffer. Fluorescence was measured using a Cytation5 plate reader (Biotek, Winooski, VT) with $530 \mathrm{~nm}$ excitation and $585 \mathrm{~nm}$ emission wavelengths. The inter- and intra-assay coefficients of variation were 3.51 and $2.60 \%$, respectively.

The body composition of the half-carcass was estimated using dual energy X-ray absorptiometry (DXA) as described by López-Campos et al. (2017). The right 
half-carcass was thawed and scanned with a Lunar iDXA unit (Lunar Prodigy Advance, General Electric, Madison, WI; Agriculture and Agri-Food Canada, Lacombe Research and Development Centre, Lacombe, $\mathrm{AB}$, Canada) using the "small animal" option on large mode ( $>20 \mathrm{~kg} ; \sim 7$ min per whole DXA table scan). Based on the different attenuation of low- and highenergy X-rays, the fat, lean, and bone tissue mass were estimated. The DXA unit was calibrated using the automated 6-point calibration and quality assurance system of Lunar iDXA twice daily to ensure there was no variation within and between experimental batches.

\section{Calculations and Statistics}

Feed efficiency was calculated as gram of BW gained per gram of DMI or MJ of ME intake. The area under the curve (AUC) for glucose and insulin was calculated using the trapezoid rule (Le Floch et al., 1990). For the IM-IVGTT, the positive (above baseline) AUC was calculated before the insulin infusion (0-20 min) and after insulin infusion (20-240 min). For the postprandial measurements, the total AUC was calculated over $600 \mathrm{~min}$.

From the sequential glucose and insulin measurements during the IM-IVGTT, 2 indices of insulin sensitivity were estimated for the period before and after insulin infusion. According to the simplified model of Pantophlet et al. (2016c),

$$
\text { Insulin sensitivity }=\mathrm{K}_{\mathrm{g}} /\left(\mathrm{AUC}_{\mathrm{ins}} / \mathrm{T}\right) \text {, }
$$

where $\mathrm{K}_{\mathrm{g}}$ (glucose disappearance rate constant; $\mathrm{min}^{-1}$ ) was estimated by converting the glucose concentration at each time point to its natural logarithm and determining the slope in Microsoft Excel (Microsoft Corp., Redmond, WA); $\mathrm{K}_{\mathrm{g}}$ was determined before (4-20 min) and after (24-50 min) the insulin infusion. The positive AUC for insulin $\left(\mathrm{AUC}_{\text {ins }}\right)$ was calculated before $(0-20$ $\mathrm{min}$ ) and after (18-50 min) insulin infusion. Second, the quantitative insulin sensitivity check index (QUICKI) was calculated with the following equation (Katz et al. (2000):

$$
\begin{gathered}
\text { QUICKI }=[1 / \log \text { baseline glucose }(\mathrm{mg} / \mathrm{dL})] \\
+\log \text { baseline insulin }(\mathrm{mU} / \mathrm{L}) .
\end{gathered}
$$

To assess treatment effects on abomasal emptying and postprandial glucose-insulin kinetics, we applied a mathematical model that allows for estimation of pancreatic responsiveness, whole-body insulin sensitivity, and glucose effectiveness (Stahel et al., 2016). Briefly, the model contains pools for abomasal acetaminophen and glucose and plasma acetaminophen, glucose, and insulin. Differential equations that describe the inputs and outputs of each pool were solved with a fourthorder Runge-Kutta algorithm in acslX (AEgis Technologies Group Inc., Huntsville, AL). Acetaminophen parameters (slow emptying rate, fast emptying rate, and utilization rate) were fit by analytically integrating the differential equation for plasma acetaminophen in Microsoft Excel and estimated for each calf using Excel Solver to minimize residual sum of squares between observed and predicted plasma acetaminophen. The parameters of glucose-insulin kinetics (endogenous synthesis, glucose effectiveness, insulin sensitivity, absorption lag time, maximum secretion, pancreatic responsiveness, glucose-dependent secretion, basal insulin mass, signaling lag time, and insulin utilization) were estimated with a differential evolution algorithm (Storn and Price, 1997) applied to the numerical simulation in acslX to minimize residual sum of squares for plasma glucose and insulin concentrations. Root mean squared prediction error as a percentage of the observed mean was calculated to indicate goodness of curve fits.

All observations were analyzed using the GLIMMIX procedure of SAS (version 9.4, SAS Institute Inc., Cary, NC). We adjusted the response distribution in the model statement to lognormal when it improved the fit of the model according to the distribution of studentized residuals and Shapiro-Wilk statistic. For data consisting of proportions, a $\beta$ distribution was used. The model included the fixed effect of treatment and random effect of block. The experimental unit was the calf. For glucose and insulin concentrations during the IM-IVGTT and postprandial on d 6 , time and treatment $\times$ time interaction were included and the covariance structure used was compound symmetry based on the lowest Akaike information criterion. Means were separated using the PDIFF statement of SAS. One HF calf missed a meal the evening before postprandial sampling; therefore, data points were removed from analysis if considered an outlier (studentized residual $<-3.4$ or $>3.4$ ). All values reported are least squares means, with significance declared at $P<0.05$ and tendencies at $0.05 \leq P<0.10$.

\section{RESULTS}

\section{Intake, Passive Transfer of Immunity, and Growth}

Passive transfer of immunity was balanced across treatment groups based on serum IgG concentration at $24 \mathrm{~h}$ after birth $(24.1$ and $25.1 \pm 0.73 \mathrm{mg} / \mathrm{mL}$ for HL and HF, respectively; $P=0.370$; data not shown). Dry 
Table 2. Least squares means of milk replacer intake, BW, and body composition of neonatal dairy calves fed a high-lactose or high-fat milk replacer until $7 \mathrm{~d}$ of age

\begin{tabular}{|c|c|c|c|c|}
\hline \multirow[b]{2}{*}{ Variable } & \multicolumn{2}{|c|}{ Milk replacer ${ }^{1}$} & \multirow[b]{2}{*}{ SEM } & \multirow[b]{2}{*}{$P$-value } \\
\hline & High lactose & High fat & & \\
\hline \multicolumn{5}{|l|}{ Total milk replacer intake until d 7} \\
\hline $\mathrm{kg}$ of DM & 4.4 & 4.5 & 0.01 & 0.283 \\
\hline Mcal of ME & 19.2 & 20.9 & 0.42 & 0.001 \\
\hline \multicolumn{5}{|l|}{ BW $(\mathrm{kg})$} \\
\hline At birth & 44.3 & 42.3 & 1.12 & 0.208 \\
\hline At d 7 & 46.8 & 46.2 & 1.11 & 0.724 \\
\hline $\operatorname{ADG}(\mathrm{g} / \mathrm{d})$ & 402.0 & 679.6 & 69.68 & 0.008 \\
\hline Gain:feed ( $\mathrm{g}$ of BW/kg) & 521.7 & 860.3 & 89.50 & 0.010 \\
\hline Gain:ME intake ( $\mathrm{g}$ of BW/Mcal) & 120.5 & 186.6 & 20.21 & 0.022 \\
\hline \multicolumn{5}{|l|}{ Body composition $^{2}(\%)$} \\
\hline Fat tissue & 24.8 & 26.2 & 0.78 & 0.266 \\
\hline Lean tissue & 70.6 & 69.3 & 0.82 & 0.248 \\
\hline Bone tissue & 4.6 & 4.5 & 0.14 & 0.754 \\
\hline
\end{tabular}

${ }^{1}$ Sloten B.V., Trouw Nutrition (Deventer, the Netherlands). High lactose $=46.1 \%$ lactose and $18.0 \%$ fat on DM basis; high fat $=39.9 \%$ lactose and $24.6 \%$ fat on a DM basis.

${ }^{2}$ Body composition was estimated using dual energy X-ray absorptiometry.

matter intake did not differ $(P=0.283)$ between treatment groups; however, by design, ME intake was $9 \%$ higher $(P=0.001)$ for HF compared with HL until d 7 (Table 2). During the 7-d study, ADG, gain:feed, and gain:ME intake were approximately 1.5 -fold greater $(P=0.008, P=0.010$, and $P=0.022$, respectively $)$ for HF compared with HL. Body composition was not significantly different for fat, lean, and bone tissue $(P=$ $0.266, P=0.248$, and $P=0.754$, respectively).

\section{Glucose and Insulin Responses During IM-IVGTT}

As shown in Table 3, glucose baseline concentration tended to be greater for HL compared with HF (7.46 vs. $7.02 \mathrm{mmol} / \mathrm{L} ; P=0.091$, whereas baseline insulin concentration did not differ $(P=0.451)$ between groups. Before the insulin infusion, time of maximum concentration $(\mathbf{T} \max )$ for insulin tended $(P=0.086)$ to be earlier for HF calves than for HL calves. Furthermore, the AUC for insulin was greater $(P=0.036)$ in HF compared with HL calves. After the insulin infusion, the starting concentration of glucose (at $18 \mathrm{~min}$ ) tended to be greater $(P=0.061)$ and the maximum change from baseline (delta) glucose concentration was greater $(3.77$ vs. $3.28 \pm 0.166 \mathrm{mmol} / \mathrm{L} ; P=0.035)$ for HL compared with HF. No differences were found for any of the other variables calculated. As indicated in Figure 1, insulin and glucose concentrations during the IM-IVGTT were unaffected by MR treatment, although a treatment $\times$ time interaction $(P<0.001)$ was found for insulin concentration during the first $20 \mathrm{~min}$ of the test.

\section{Postprandial Glucose, Insulin, and Acetaminophen Responses}

A treatment $\times$ time interaction $(P=0.003$, Figure 2) was observed for postprandial concentrations of acetaminophen. Abomasal emptying rate was lower in calves fed the HF MR $(P=0.039$, Table 4$)$ compared with calves fed HL. A tendency for an interaction of treatment $\times$ time $(P=0.065$, Figure 2$)$ was observed for postprandial concentrations of glucose. Similarly, a treatment $\times$ time interaction was observed $(P=0.005$, Figure 2) for postprandial plasma insulin concentrations. In addition, as shown in Table 5 , the baseline, maximum plasma concentration (Cmax), and AUC for plasma glucose were or tended to be lower by $5 \%$ $(P=0.046), 9 \%(P=0.031)$, and $7 \%(P=0.071)$, respectively, in HF compared with HL. The HF treatment decreased Cmax, delta, Cmax:Tmax, and AUC of plasma insulin by $32 \%(P=0.032), 37 \%(P=0.032)$, $37 \%(P=0.035)$, and $25 \%(P=0.022)$, respectively, compared with HL. No differences were found for other variables calculated.

\section{Pancreas and Liver}

Pancreas weight did not differ $(P=0.353)$ between treatment groups (Table 6). Furthermore, the number of cells in and size of the islets of Langerhans were similar ( $P=0.572$ and $P=0.638$, respectively) for both treatment groups. However, the liver was $10 \%$ heavier (1,378 vs. $1,239 \mathrm{~g} ; P=0.002)$ and contained $50 \%$ more glycogen ( 26.5 vs. $17.7 \mathrm{mg} / \mathrm{g} ; P=0.002)$ in HL compared with HF calves. 


\section{DISCUSSION}

In recent years, there has been a shift toward feeding dairy calves more milk to more closely meet their nutrient requirements for their biological potential for BW gain (>8 vs. $4 \mathrm{~L} / \mathrm{d}$ or $>1,000$ vs. $500 \mathrm{~g}$ of $\mathrm{MR} / \mathrm{d}$; MacPherson et al., 2016). However, the macronutrient composition of the formulation should also be considered. In the current study, lactose was replaced with fat on a weight/weight basis, resulting in a higher ME content of the HF compared with the HL MR (4.49 vs. $4.23 \mathrm{Mcal} / \mathrm{kg}$ of $\mathrm{DM}$ ). Neither meal size nor amount of solids were adjusted to achieve isocaloric intakes. This approach allows for studying responses to different nutrient profiles of the solids fraction of the milk supplied to calves. In essence, the differences in solids composition between the most commonly available MR formulations (high lactose and low fat) and whole milk are contrasted. Additionally, this approach prevents effects of meal volume on postprandial variables, such as abomasal emptying (MacPherson et al., 2016). On that note, previous work shows that partially replacing lactose in MR with fat can reduce DMI from MR when fed ad libitum, potentially as a means to regulate ME intake (Echeverry-Munera et al., 2020). The calves in the current study were restricted to ensure similar DMI in both treatment groups. Therefore, despite a similar total DMI for both treatment groups, total ME intake was, by study design, greater for HF compared with HL. A greater ME intake results in higher growth rates (Khan et al., 2011), as reflected by the $60 \%$ increase in growth over the 7-d period for HF compared with HL calves (3.90 vs. $2.44 \mathrm{~kg}$, respectively). Calculating the growth per megacalorie intake (gain:ME intake) shows a $55 \%$ increase in feed efficiency for HF compared with HL. Tikofsky et al. (2001) indicated the importance of isocaloric and isonitrogenous intakes when evaluating effects of macronutrient composition on growth. Because the MR in the current study were isonitrogenous but not isocaloric, the HF calves may have had

Table 3. Least squares means of glucose and insulin responses measured during an insulin-modified intravenous glucose tolerance test on d 4 of life in neonatal dairy calves fed a high-lactose or high-fat milk replacer

\begin{tabular}{|c|c|c|c|c|}
\hline \multirow[b]{2}{*}{ Variable $^{1}$} & \multicolumn{2}{|c|}{ Milk replacer ${ }^{2}$} & \multirow[b]{2}{*}{ SEM } & \multirow[b]{2}{*}{$P$-value } \\
\hline & High lactose & High fat & & \\
\hline \multicolumn{5}{|l|}{ Before insulin infusion } \\
\hline \multicolumn{5}{|l|}{ Glucose } \\
\hline Baseline $(\mathrm{mmol} / \mathrm{L})$ & 7.46 & 7.02 & 0.177 & 0.091 \\
\hline $\mathrm{Cmax}^{3}(\mathrm{mmol} / \mathrm{L})$ & 12.00 & 11.96 & 0.477 & 0.967 \\
\hline $\operatorname{Delta}^{3}(\mathrm{mmol} / \mathrm{L})$ & 4.42 & 4.76 & 0.390 & 0.628 \\
\hline $\mathrm{AUC}_{0-20 \min }^{3}(\mathrm{mmol} / \mathrm{L} \times \min )$ & 41.34 & 42.64 & 2.075 & 0.677 \\
\hline Disappearance rate $\left(\mathrm{min}^{-1}\right)$ & 0.0010 & 0.0079 & 0.00104 & 0.179 \\
\hline \multicolumn{5}{|l|}{ Insulin } \\
\hline Baseline $(\mu \mathrm{g} / \mathrm{L})$ & 0.24 & 0.28 & 0.037 & 0.451 \\
\hline $\operatorname{Cmax}^{3}(\mu \mathrm{g} / \mathrm{L})$ & 0.70 & 0.95 & 0.108 & 0.149 \\
\hline$T \max (\min )$ & 14.24 & 11.88 & 0.886 & 0.086 \\
\hline $\operatorname{Delta}^{3}(\mu \mathrm{g} / \mathrm{L})$ & 0.45 & 0.67 & 0.088 & 0.103 \\
\hline $\mathrm{AUC}_{0-20 \mathrm{~min}}(\mu \mathrm{g} / \mathrm{L} \times \min )$ & 3.90 & 6.91 & 0.967 & 0.036 \\
\hline Insulin sensitivity $^{3}[\mathrm{~L} /(\mu \mathrm{g} \times \min )]$ & 0.028 & 0.030 & 0.0085 & 0.883 \\
\hline Insulin sensitivity (QUICKI) & 0.37 & 0.36 & 0.011 & 0.448 \\
\hline \multicolumn{5}{|l|}{ After insulin infusion } \\
\hline \multicolumn{5}{|l|}{ Glucose } \\
\hline Starting concentration $(\mathrm{mmol} / \mathrm{L})$ & 9.33 & 8.61 & 0.255 & 0.061 \\
\hline $\mathrm{Cmin}^{3}(\mathrm{mmol} / \mathrm{L})$ & 5.41 & 5.25 & 0.187 & 0.594 \\
\hline Delta $^{3}(\mathrm{mmol} / \mathrm{L})$ & 3.77 & 3.28 & 0.166 & 0.035 \\
\hline $\mathrm{AUC}_{18-240 \min }{ }^{3}(\mathrm{mmol} / \mathrm{L} \times \min )$ & 18.45 & 14.73 & 3.531 & 0.473 \\
\hline Disappearance rate $\left(\mathrm{min}^{-1}\right)$ & 0.0113 & 0.0117 & 0.00136 & 0.797 \\
\hline \multicolumn{5}{|l|}{ Insulin } \\
\hline Starting concentration ${ }^{3}(\mu \mathrm{g} / \mathrm{L})$ & 0.57 & 0.64 & 0.088 & 0.614 \\
\hline $\mathrm{Cmax}(\mu \mathrm{g} / \mathrm{L})$ & 9.71 & 9.45 & 1.035 & 0.862 \\
\hline $\operatorname{Delta}^{3}(\mu \mathrm{g} / \mathrm{L})$ & 8.99 & 8.69 & 1.002 & 0.834 \\
\hline $\mathrm{AUC}_{18-240 \min }{ }^{3}(\mu \mathrm{g} / \mathrm{L} \times \min )$ & 60.99 & 59.12 & 5.912 & 0.829 \\
\hline Insulin sensitivity $[\mathrm{L} /(\mu \mathrm{g} \times \mathrm{min})]$ & 0.0058 & 0.0064 & 0.00068 & 0.543 \\
\hline
\end{tabular}

${ }^{1} \mathrm{Cmax}=$ maximum plasma concentration; delta $=$ maximum change from baseline; $\mathrm{AUC}=$ positive incremental area under the curve; Tmax = time of maximum concentration; QUICKI = quantitative insulin sensitivity check index; Cmin = minimum plasma concentration.

${ }^{2}$ Sloten B.V., Trouw Nutrition (Deventer, the Netherlands). High lactose $=46.1 \%$ lactose and $18.0 \%$ fat on DM basis; high fat $=39.9 \%$ lactose and $24.6 \%$ fat on DM basis.

${ }^{3}$ Least squares means and SEM are back transformed to the original scale. 
more energy available for retention after maintenance requirements were met compared with HL (Tikofsky et al., 2001). However, if more energy became available for retention in calves fed the HF MR, this did not result in statistically detectable differences in body composition; this is in contrast with previous studies (Donnelly, 1983; Tikofsky et al., 2001; Bascom et al., 2007) that found that increasing the fat content of MR increased fat deposition in Holstein-Friesian and Jersey bull calves during the first 2 mo of life. The discrepancies between the current study and previous studies could be due to unexpectedly high variation in the measurements of body composition, resulting in insufficient statistical power to detect a difference in body composition (0.24; POWER procedure using SAS). In addition, in previous studies, treatment diets contained up to $32 \%$ fat on a DM basis (compared with $25 \%$ of DM in our study) and a slightly higher CP content (27-29\% compared with $24 \%$ of DM in our study), and calves were fed for a longer time (e.g., for 28-55 d; Donnelly, 1983; Tikofsky et al., 2001; Bascom et al., 2007), potentially allowing greater differences in fat deposition to develop.
Although body composition was unaffected by MR treatment in the current study, altering the macronutrient composition did result in digestive and metabolic consequences. The delayed abomasal emptying in HF was in agreement with what we expected based on the higher caloric density of HF. Osmolality of the MR was not likely a contributing factor because osmolalities did not differ greatly (490 vs. $457 \mathrm{mOsm} / \mathrm{kg}$ for HL vs. HF; Advanced Instruments 3300 Micro-Osmometer, Norwood, MA). Similarly, Bell and McLeay (1978) found that duodenal fat infusion resulted in a stronger reduction in abomasal emptying compared with a duodenal lactose infusion in 3-wk-old dairy calves. A potential mechanism involves the hormone cholecystokinin, as ingesting fat stimulates release of cholecystokinin and intravenously infusing cholecystokinin slows abomasal emptying (Bell and McLeay, 1978; Liddle et al., 1985, 1986). A delay in abomasal emptying might be beneficial because it could increase abomasal clotting and, subsequently, delay digestion of protein and fat, allowing for a steady supply of absorbable nutrients (Bell and McLeay, 1978). However, the same MR used in

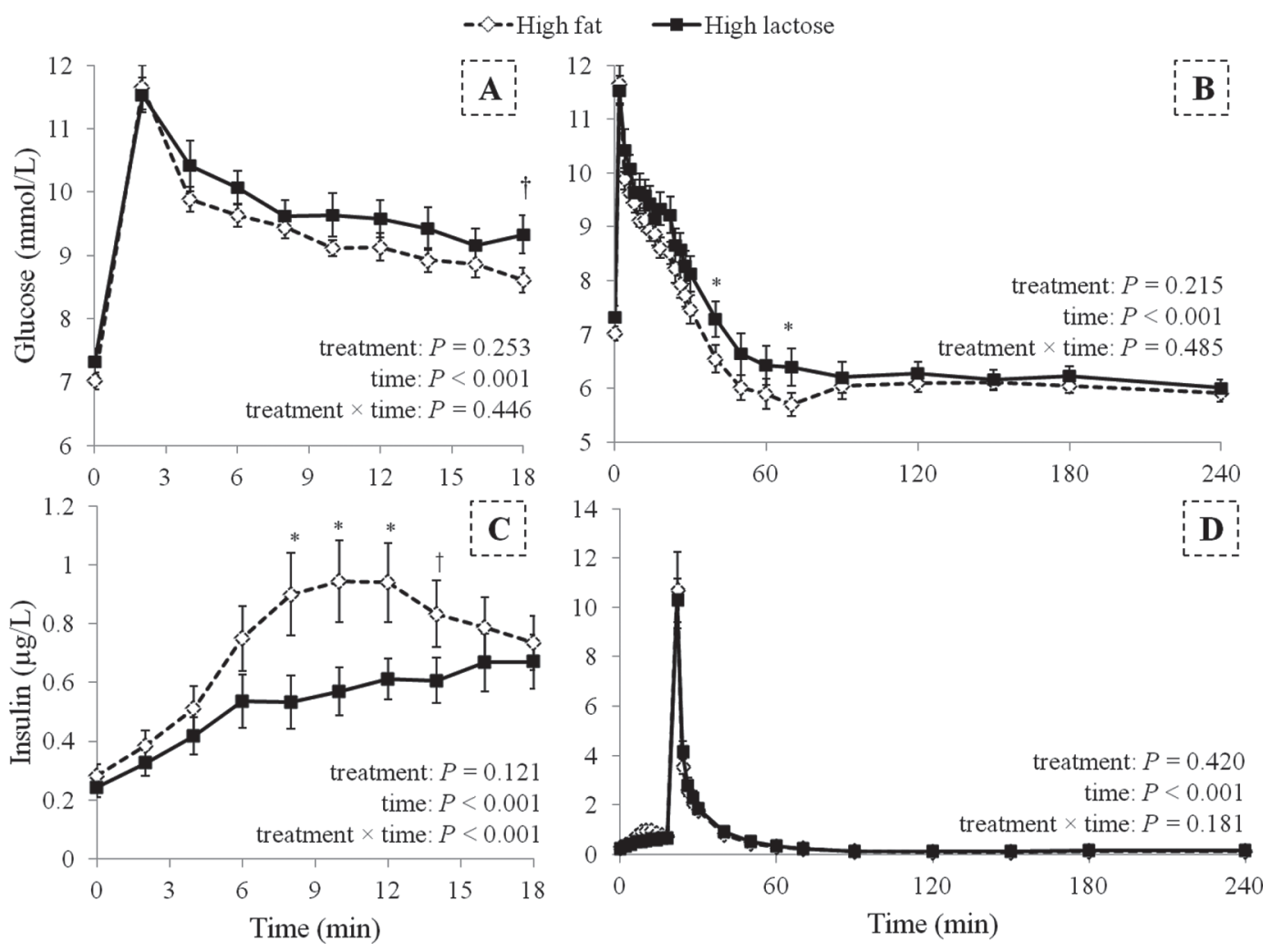

Figure 1. Plasma glucose and insulin concentrations during an insulin-modified intravenous glucose tolerance test on d 4 of life in calves fed a high-lactose (46.1\% lactose and $18.0 \%$ fat on a DM basis) or high-fat (39.9\% lactose and $24.6 \%$ fat on a DM basis) milk replacer. (A) Glucose concentrations before insulin infusion, (B) glucose concentrations during entire test, $(\mathrm{C})$ insulin concentrations before insulin infusion, and (D) insulin concentrations during entire test. Data points are mean $\pm \mathrm{SE} ;{ }^{*} P<0.05, \dagger P<0.10$. 
the current study were evaluated in dairy bull calves, and at $4 \mathrm{wk}$ of age no differences in apparent totaltract digestibility of DM, CP, crude fat, and crude ash between treatment groups were detected (Amado et al., 2019). Furthermore, the delay in abomasal emptying found in the current study could be beneficial in terms of regulating glucose homeostasis as discussed below.

Dietary glucose intake and the subsequent inflow of dietary glucose into the duodenum, which is regu- lated by abomasal emptying, play a role in maintaining glucose homeostasis. Therefore, in HL calves, greater quantities of MR containing more lactose entered the small intestine per unit of time, causing a greater increase in postprandial glucose and insulin concentrations in plasma. Moreover, the greater lactose intake in HL increased the supply of energy precursors for storage in the liver in the form of glycogen. Potentially, lactose-derived galactose may have played a major role,

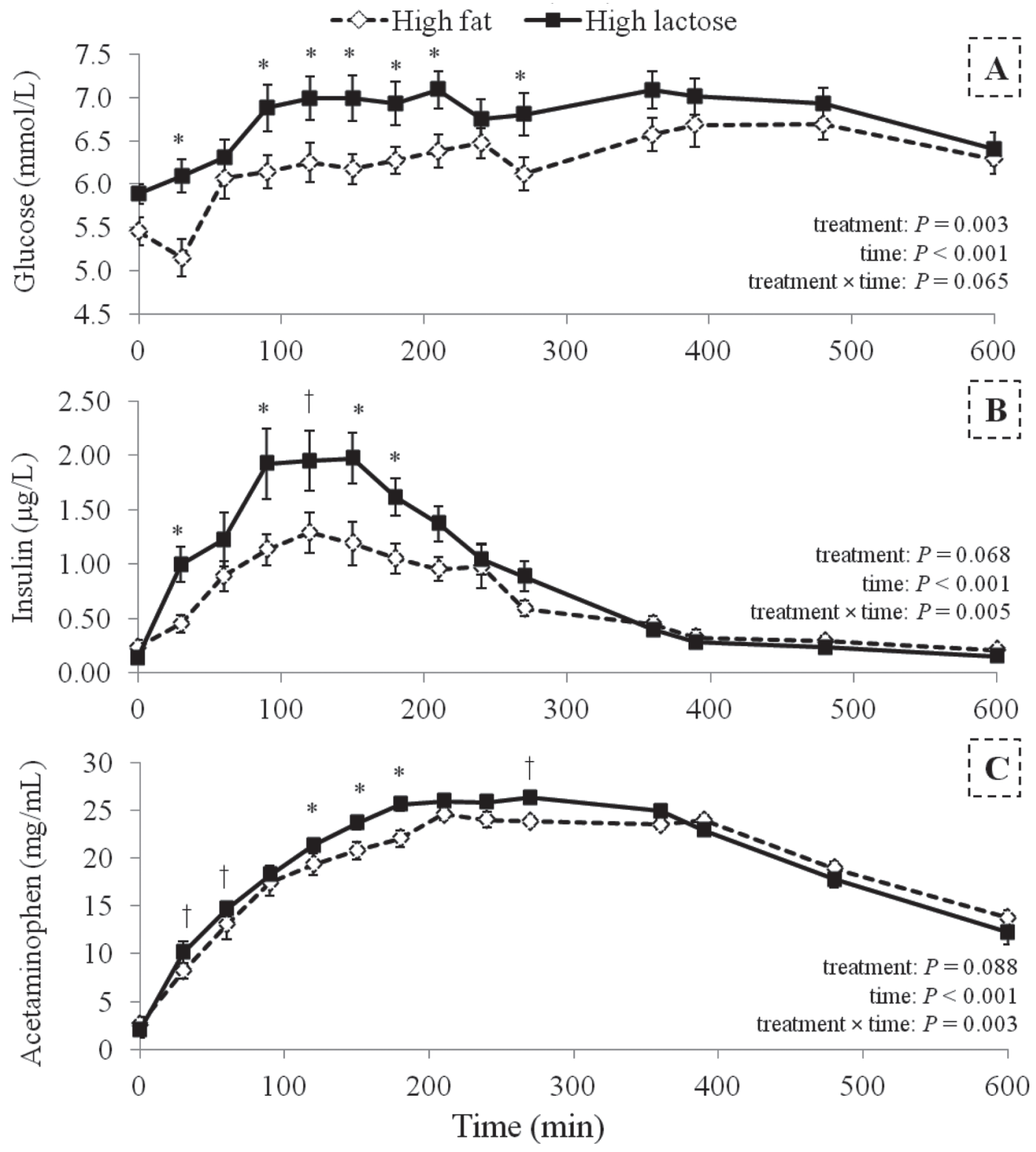

Figure 2. Plasma (A) glucose, (B) insulin, and (C) acetaminophen concentrations during postprandial sampling on d 6 of life in calves fed a high-lactose (46.1\% lactose and $18.0 \%$ fat on a DM basis) or high-fat (39.9\% lactose and $24.6 \%$ fat on a DM basis) milk replacer. Data points are mean $\pm \mathrm{SE} ;{ }^{*} P<0.05, \dagger P<0.10$ 
Table 4. Least squares means of abomasal emptying and glucose-insulin dynamics during postprandial sampling on d 6 of life in neonatal dairy calves fed a high-lactose or high-fat milk replacer ${ }^{1}$

\begin{tabular}{|c|c|c|c|c|c|c|}
\hline Variable $^{2}$ & Abbreviation & High lactose & $\mathrm{SE}$ & High fat & $\mathrm{SE}$ & $P$-value \\
\hline \multicolumn{7}{|l|}{ Acetaminophen } \\
\hline Slow emptying rate $\left(\mathrm{min}^{-1}\right)$ & $\mathrm{k}_{\mathrm{SP}, 2}$ & 0.0025 & 0.00037 & 0.0015 & 0.00022 & 0.039 \\
\hline \multicolumn{7}{|l|}{ Glucose } \\
\hline Endogenous synthesis $\left(\mathrm{mmol} \cdot \mathrm{min}^{-1}\right)$ & $\mathrm{PGl}_{\text {end }}$ & 0.0421 & 0.03038 & 0.0369 & 0.02666 & 0.876 \\
\hline Glucose effectiveness $\left(\mathrm{L} \cdot \mathrm{min}^{-1}\right)$ & $\mathrm{k}_{\mathrm{Gl}, \mathrm{UGl}}$ & 0.0022 & 0.00149 & 0.0013 & 0.00089 & 0.348 \\
\hline $\mathrm{rMSPE}_{\mathrm{G}}(\%$ of mean $)$ & & 9.8 & 0.88 & 10.3 & 0.88 & 0.723 \\
\hline \multicolumn{7}{|l|}{ Insulin } \\
\hline Maximum secretion $\left(\mu \mathrm{g} \cdot \min ^{-1}\right)$ & $\mathrm{V}_{\mathrm{PIn}}$ & $1,307.85$ & 657.305 & $1,845.89$ & 927.716 & 0.678 \\
\hline Glucose-dependent secretion $(\mathrm{m} M)$ & $\mathrm{K}_{\mathrm{Gl}, \mathrm{PIn}}$ & 8.04 & 0.863 & 10.27 & 1.103 & 0.251 \\
\hline Pancreatic responsiveness & $\exp _{\text {Pin }}$ & 16.91 & 3.835 & 14.49 & 3.288 & 0.654 \\
\hline Basal insulin mass $(\mu \mathrm{g})$ & iIn & 1.61 & 0.005 & 1.74 & 0.005 & 0.849 \\
\hline Signaling lag time $\left(\mathrm{min}^{-1}\right)$ & $\mathrm{T}_{\text {lag. In }}$ & 1.36 & 0.955 & 0.90 & 0.631 & 0.685 \\
\hline
\end{tabular}

${ }^{1}$ Sloten B.V., Trouw Nutrition (Deventer, the Netherlands). High lactose $=46.1 \%$ lactose and $18.0 \%$ fat on DM basis; high fat $=39.9 \%$ lactose and $24.6 \%$ fat on DM basis.

${ }^{2}$ Least squares means and $\mathrm{SE}$ of all variables are back transformed to the original scale, except for $\mathrm{T}_{\text {lag,SB}}$, root mean squared prediction error of glucose $\left(\mathrm{rMSPE}_{\mathrm{G}}\right)$, iIn and root mean squared prediction error of insulin $\left(\mathrm{rMSPE}_{\mathrm{I}}\right)$.

as Barosa et al. (2012) found that essentially all milk galactose was converted to hepatic glycogen in healthy human subjects that consumed milk during breakfast.

The higher baseline glucose in HL compared with HF calves on d 6 may imply a greater challenge to maintain glucose homeostasis. However, on average, calves did not experience hyperglycemia, as defined by the renal threshold for glucosuria in Holstein-Friesian and Simmental $\times$ Red Holstein bull calves at blood concentrations of 8.3 to $11.1 \mathrm{mmol} / \mathrm{L}$ (Wijayasinghe et al., 1984; Hostettler-Allen et al., 1994). Seven calves (5 HL and $2 \mathrm{HF}$ ) experienced plasma glucose concentrations greater than $8.3 \mathrm{mmol} / \mathrm{L}$ during postprandial sampling; however, none of the calves exceeded 10.0 mmol/L. Moreover, postprandial baseline and Cmax plasma concentrations of glucose and insulin in the

Table 5. Least squares means of glucose and insulin responses measured during postprandial sampling on d 6 of life in neonatal dairy calves fed a high-lactose or high-fat milk replacer

\begin{tabular}{|c|c|c|c|c|}
\hline \multirow[b]{2}{*}{ Variable $^{1}$} & \multicolumn{2}{|c|}{ Milk replacer $^{2}$} & \multirow[b]{2}{*}{ SEM } & \multirow[b]{2}{*}{$P$-value } \\
\hline & High lactose & High fat & & \\
\hline \multicolumn{5}{|l|}{ Glucose } \\
\hline Baseline $(\mathrm{mmol} / \mathrm{L})$ & 5.89 & 5.61 & 0.102 & 0.046 \\
\hline $\operatorname{Cmax}(\mathrm{mmol} / \mathrm{L})$ & 8.01 & 7.30 & 0.210 & 0.031 \\
\hline Delta $(\mathrm{mmol} / \mathrm{L})$ & 2.12 & 1.85 & 0.199 & 0.378 \\
\hline $\operatorname{Tmax}(\min )$ & 234.71 & 254.12 & 33.112 & 0.619 \\
\hline Cmax:Tmax ${ }^{3}$ & 0.04 & 0.03 & 0.005 & 0.549 \\
\hline $\mathrm{AUC}_{0-600 \min }(\mathrm{mmol} / \mathrm{L} \times \min )$ & $4,027.77$ & $3,744.73$ & 102.790 & 0.071 \\
\hline \multicolumn{5}{|l|}{ Insulin } \\
\hline Baseline $^{3}(\mu \mathrm{g} / \mathrm{L})$ & 0.12 & 0.14 & 0.025 & 0.528 \\
\hline $\operatorname{Cmax}^{3}(\mu \mathrm{g} / \mathrm{L})$ & 2.48 & 1.69 & 0.219 & 0.032 \\
\hline Delta $(\mu \mathrm{g} / \mathrm{L})$ & 2.57 & 1.62 & 0.271 & 0.032 \\
\hline $\operatorname{Tmax}(\min )$ & 134.12 & 162.35 & 15.666 & 0.135 \\
\hline Cmax:Tmax & 0.019 & 0.012 & 0.002 & 0.035 \\
\hline $\mathrm{AUC}_{0-600 \min }(\mathrm{ug} / \mathrm{L} \times \min )$ & 491.79 & 368.07 & 31.201 & 0.022 \\
\hline Glucose $\mathrm{AUC}_{0-600}$ :insulin $\mathrm{AUC}_{0-600}{ }^{3}$ & 8.52 & 10.62 & 0.750 & 0.115 \\
\hline
\end{tabular}

${ }^{1} \mathrm{Cmax}=$ maximum plasma concentration; delta $=$ maximum change from baseline; Tmax $=$ time of maximum concentration; $\mathrm{AUC}_{0-600}=$ area under the curve from 0 to 600 min relative to meal.

${ }^{2}$ Sloten B.V., Trouw Nutrition (Deventer, the Netherlands). High lactose $=46.1 \%$ lactose and $18.0 \%$ fat on DM basis; high fat $=39.9 \%$ lactose and $24.6 \%$ fat on DM basis.

${ }^{3}$ Least squares means and SEM are back transformed to the original scale. 
Table 6. Least squares means of pancreas and liver variables in 7-d-old dairy calves fed a high-lactose or high-fat milk replacer

\begin{tabular}{lcrrr}
\hline & \multicolumn{2}{c}{ Milk replacer ${ }^{1}$} & & \\
\cline { 2 - 3 } Variable & High lactose & \multirow{2}{*}{ High fat } & SEM & $P$-value \\
\hline Pancreas weight $^{2}(\mathrm{~g})$ & 29.16 & 27.96 & 1.706 & 0.510 \\
Islet of Langerhans size $\left(\mu \mathrm{m}^{2}\right)$ & $7,067.38$ & $6,548.86$ & 658.245 & 0.572 \\
Islet of Langerhans cell count & 4.35 & 4.30 & 0.094 & 0.638 \\
Liver weight $(\mathrm{g})$ & $1,377.82$ & $1,239.24$ & 34.529 & 0.002 \\
Liver glycogen $(\mathrm{mg} / \mathrm{g}$ of wet tissue) & 26.50 & 17.69 & 2.041 & 0.002 \\
\hline${ }^{1}$ Sloten B.V., Trouw Nutrition (Deventer, the Netherlands). High lactose $=46.1 \%$ lactose and $18.0 \%$ fat on DM \\
basis; high fat = 39.9\% lactose and $24.6 \%$ fat on DM basis. & & & \\
${ }^{2}$ Least squares means and SEM are back transformed to the original scale. & &
\end{tabular}

current study were similar to those in previous studies conducted with neonatal dairy calves fed $\geq 8 \mathrm{~L} / \mathrm{d}$ of MR containing $45 \%$ lactose on a DM basis (MacPherson et al., 2016; Pantophlet et al., 2016b). Therefore, the differences between the treatment groups can be considered minor as the glucose and insulin concentrations return to normal baseline levels.

In the current study, an IM-IVGTT was performed to evaluate pancreatic responsiveness and insulin sensitivity in response to altering macronutrient composition of MR. The pancreatic response (i.e., the quantity of insulin secreted in response to a glucose stimulus) was evaluated from plasma insulin concentrations during the first $20 \mathrm{~min}$ of the test. Then, insulin was infused to suppress hepatic glucose synthesis and improve estimation of insulin sensitivity from glucose clearance out of plasma (Yang et al., 1987). The pancreatic response was increased in HF compared with HL (greater positive AUC for plasma insulin after intravenous glucose and before insulin injection), although this did not alter the size and cell count of islets of Langerhans. The effect of dietary fat directly on pancreatic $\beta$-cells might have caused this response, as demonstrated in rats fed a high-fat diet compared with a low-fat diet (22 or $40 \%$ vs. 4\%; Holness, 1996; Dobbins et al., 2002). A potential mechanism behind this response could be pancreatic exposure to elevated free fatty acids that increase de novo synthesis of islet phospholipids involved in insulin release (Vara and Tamarit-Rodriguez, 1986; Vara et al., 1988).

Postprandial insulin sensitivity tended to be reduced and the ratio of glucose AUC:insulin AUC over 600 min was numerically lower in HL compared with HF. This suggests that calves fed HL tended to require more insulin per unit of dietary glucose in response to their meal to reduce plasma glucose concentrations compared with HF. Interestingly, feeding the same HL ( $44 \%$ of DM) or HF (23\% of DM) MR during the first 4 wk of life did not affect postprandial insulin sensitivity at $30 \mathrm{~d}$ of age (Stahel et al., 2019), potentially due to the ability to adapt to an HL diet (Hof, 1980). Therefore, this study is highly unique as it evaluates animals during their first week of life, a phase in which intake, animal growth, and metabolism can be highly variable. However, our data from the IM-IVGTT indicate that the macronutrient compositions of the MR used in the current study did not affect fasting insulin sensitivity. This finding agrees with Pantophlet et al. (2016a), who demonstrated that isocaloric replacement of lactose in MR with fat ( $34 \%$ vs. $59 \%$ lactose on a DM basis) did not alter fasting insulin sensitivity in 99-d-old HolsteinFriesian bull calves when fed for 13 wk at $>1,000 \mathrm{~g}$ of $\mathrm{MR} / \mathrm{d}$. The authors ascribed the lack of difference to the low insulin sensitivity due to age in their calves compared with younger ones. Potentially, in our study the difference in macronutrient composition of the MR may not have been broad enough ( $46 \%$ vs. $40 \%$ lactose on a DM basis) or the exposure not long enough to elicit an effect on fasting insulin sensitivity. The discrepancy between insulin sensitivity estimated from the IM-IVGTT and postprandial sampling is due to the acute influence of fats, proteins, and other constituents in the MR on enzyme and signaling activities in tissues, including the gastrointestinal tract, and therefore, the postprandial test better represents the physiological challenge calves face after consuming a meal (Berthiaume and Zinker, 2002).

\section{CONCLUSIONS}

The results of this study demonstrate that partially replacing lactose in MR formulation with fat increased BW gain as well as gain:ME intake in neonatal dairy calves during the first week of life. Furthermore, feeding a high-fat MR slowed abomasal emptying and reduced postprandial glucose and insulin concentrations. Postprandial insulin sensitivity tended to be reduced in HL compared with HF. However, there was no evidence of hyperglycemia in the calves fed the high-lactose MR, and the glucose and insulin concentrations returned to 
baseline concentrations. Additionally, fasting insulin sensitivity, as determined from IM-IVGTT data, was not different between treatments, but HF enhanced glucose-stimulated insulin secretion. Overall, partially replacing lactose with fat to mimic the macronutrient composition of whole milk may benefit growth with minor alterations in glucose homeostasis in neonatal dairy calves.

\section{ACKNOWLEDGMENTS}

The authors gratefully acknowledge the staff of the Dairy Research and Technology Centre (University of Alberta, Edmonton, AB, Canada) for their assistance with the animal experiment. The authors thank the funding support provided by Alberta Milk (Edmonton, AB, Canada), BC Dairy Association (Burnaby, BC, Canada), Dairy Farmers of Manitoba (Winnipeg, MB, Canada), SaskMilk (Regina, SK, Canada), Trouw Nutrition (Amersfoort, the Netherlands), the Saskatoon Colostrum Co. Ltd. (Saskatoon, SK, Canada), Bayer (Leverkusen, Germany), Lallemand Animal Nutrition (Montreal, QC, Canada), Westgen (Abbotsford, BC, Canada), and National Science and Engineering Research Council (Ottawa, ON, Canada). The authors have not stated any conflicts of interest.

\section{REFERENCES}

Amado, L., H. Berends, L. N. Leal, J. Wilms, H. Van Laar, W. J. J. Gerrits, and J. Martín-Tereso. 2019. Effect of energy source in calf milk replacer on performance, digestibility, and gut permeability in rearing calves. J. Dairy Sci. 102:3994-4001. https://doi.org/10 $.3168 /$ jds.2018-15847.

Barosa, C., C. Silva, A. Fagulha, L. Barros, M. M. Caldeira, M. Carvalheiro, and J. G. Jones. 2012. Sources of hepatic glycogen synthesis following a milk-containing breakfast meal in healthy subjects. Metabolism 61:250-254. https://doi.org/10.1016/j.metabol.2011 .06 .022 .

Bascom, S. A., R. E. James, M. L. McGilliard, and M. Van Amburgh. 2007. Influence of dietary fat and protein on body composition of Jersey bull calves. J. Dairy Sci. 90:5600-5609. https://doi.org/10 $.3168 / j d s .2007-0004$.

Bell, F. R., and L. M. McLeay. 1978. The effect of duodenal infusion of milk, casein, lactose and fat on gastric emptying and acid secretion in the milk-fed calf. J. Physiol. 282:51-57. https://doi.org/10 .1113/jphysiol.1978.sp012447.

Berthiaume, N., and B. A. Zinker. 2002. Metabolic responses in a model of insulin resistance: Comparison between oral glucose and meal tolerance tests. Metabolism 51:595-598. https://doi.org/10 .1053/meta.2002.31989.

CCAC (Canadian Council on Animal Care). 1993. Guide to the Care and Use of Experimental Animals. Vol. 1. http://www.ccac.ca/.

Dobbins, R. L., L. S. Szczepaniak, J. Myhill, Y. Tamura, H. Uchino, A. Giacca, and J. D. McGarry. 2002. The composition of dietary fat directly influences glucose-stimulated insulin secretion in rats. Diabetes 51:1825-1833. https://doi.org/10.2337/diabetes.51.6.1825.

Donnelly, P. E. 1983. Effects of dietary carbohydrate:fat ratio on growth and body composition of milk-fed calves. N. Z. J. Agric. Res. 26:71-77. https://doi.org/10.1080/00288233.1983.10420953.

Echeverry-Munera, J., L. Leal, J. Wilms, H. Berends, M. A. Steele, and J. Martín-Tereso. 2020. Effect of dietary energy source re- placement in calf milk replacer fed ad libitum on voluntary feed intake and performance in dairy calves. J. Dairy Sci. 103(Suppl. 1):55. (Abstr.)

Hof, G. 1980. An investigation into the extent to which various dietary components, particularly lactose, are related to the incidence of diarrhoea in milk-fed calves. PhD Diss. Wageningen University, Wageningen, the Netherlands.

Holness, M. J. 1996. The influence of sub-optimal protein nutrition on insulin hypersecretion evoked by high-energy/high-fat feeding in rats. FEBS Lett. 396:53-56. https://doi.org/10.1016/0014 $-5793(96) 01067-8$.

Hostettler-Allen, R. L., L. Tappy, and J. W. Blum. 1994. Insulin resistance, hyperglycemia, and glucosuria in intensively milk-fed calves. J. Anim. Sci. 72:160-173. https://doi.org/10.2527/1994.721160x.

Hugi, D., R. M. Bruckmaier, and J. W. Blum. 1997. Insulin resistance, hyperglycemia, glucosuria, and galactosuria in intensively milkfed calves: Dependency on age and effects of high lactose intake. J. Anim. Sci. 75:469-482. https://doi.org/10.2527/1997.752469x.

Katz, A., S. S. Nambi, K. Mather, A. D. Baron, D. A. Follmann, G. Sullivan, and M. J. Quon. 2000. Quantitative insulin sensitivity check index: A simple, accurate method for assessing insulin sensitivity in humans. J. Clin. Endocrinol. Metab. 85:2402-2410. https: //doi.org/10.1210/jcem.85.7.6661.

Khan, M. A., D. M. Weary, and M. A. G. Von Keyserlingk. 2011. Invited review: Effects of milk ration on solid feed intake, weaning, and performance in dairy heifers. J. Dairy Sci. 94:1071-1081. https://doi.org/10.3168/jds.2010-3733.

Le Floch, J. P., P. Escuyer, E. Baudin, D. Baudon, and L. Perlemuter. 1990. Blood glucose area under the curve: Methodological aspects. Diabetes Care 13:172-175. https://doi.org/10.2337/diacare.13.2 .172 .

Lee, H. J., M. A. Khan, W. S. Lee, S. H. Yang, S. B. Kim, K. S. Ki, H. S. Kim, J. K. Ha, and Y. J. Choi. 2009. Influence of equalizing the gross composition of milk replacer to that of whole milk on the performance of Holstein calves. J. Anim. Sci. 87:1129-1137. https: //doi.org/10.2527/jas.2008-1110.

Liddle, R. A., I. D. Goldfine, M. S. Rosen, R. A. Taplitz, and J. A. Williams. 1985. Cholecystokinin bioactivity in human plasma. Molecular forms, responses to feeding, and relationship to gallbladder contraction. J. Clin. Invest. 75:1144-1152. https://doi.org/10 $.1172 /$ JCI111809.

Liddle, R. A., E. T. Morita, C. K. Conrad, and J. A. Williams. 1986. Regulation of gastric emptying in humans by cholecystokinin. J. Clin. Invest. 77:992-996. https://doi.org/10.1172/JCI112401.

López-Campos, O., I. L. Larsen, N. Prieto, M. Juarez, M. E. R. Dugan, and J. L. Aalhus. 2017. Evaluation of total lean and saleable meat yield prediction equations and dual energy X-ray absorptiometry for a rapid, non-invasive yield prediction in beef. Meat Sci. 1:104. https://doi.org/10.22175/rmc2016.101.

MacPherson, J. A. R., H. Berends, L. N. Leal, J. P. Cant, J. MartínTereso, and M. A. Steele. 2016. Effect of plane of milk replacer intake and age on glucose and insulin kinetics and abomasal emptying in female Holstein Friesian dairy calves fed twice daily. J. Dairy Sci. 99:8007-8017. https://doi.org/10.3168/jds.2015-10826.

Mann, S., F. A. Leal Yepes, J. J. Wakshlag, E. Behling-Kelly, and J. A. A. McArt. 2018. The effect of different treatments for earlylactation hyperketonemia on liver triglycerides, glycogen, and expression of key metabolic enzymes in dairy cattle. J. Dairy Sci. 101:1626-1637. https://doi.org/10.3168/jds.2017-13360.

Pantophlet, A. J., W. J. J. Gerrits, R. J. Vonk, and J. J. G. C. van den Borne. 2016a. Substantial replacement of lactose with fat in a high-lactose milk replacer diet increases liver fat accumulation but does not affect insulin sensitivity in veal calves. J. Dairy Sci. 99:10022-10032. https://doi.org/10.3168/jds.2016-11524.

Pantophlet, A. J., M. S. Gilbert, J. J. van den Borne, W. J. Gerrits, H. Roelofsen, M. G. Priebe, and R. J. Vonk. 2016b. Lactose in milk replacer can partly be replaced by glucose, fructose, or glycerol without affecting insulin sensitivity in veal calves. J. Dairy Sci. 99:3072-3080. https://doi.org/10.3168/jds.2015-10277.

Pantophlet, A. J., M. S. Gilbert, J. J. G. C. Van Den Borne, W. J. J. Gerrits, M. G. Priebe, and R. J. Vonk. 2016c. Insulin sensitivity in 
calves decreases substantially during the first 3 months of life and is unaffected by weaning or fructo-oligosaccharide supplementation. J. Dairy Sci. 99:7602-7611. https://doi.org/10.3168/jds.2016 -11084 .

Schaer, S., M. Herrli-Gygi, N. Kosmeas, H. Boschung, and A. Steiner. 2005. Characteristics of acetaminophen absorption in healthy unweaned calves as an indirect measurement of the oroduodenal transit rate of liquid meals. J. Vet. Med. A Physiol. Pathol. Clin. Med. 52:325-332. https://doi.org/10.1111/j.1439-0442.2005.00738 .x.

Stahel, P.. H. Berends, L. N. Leal, and J. Martín-Tereso. 2019. Effect of replacing lactose with fat in milk replacer on abomasal emptying and glucose-insulin kinetics in male dairy calves. Appl. Anim. Sci. 35:586-595. https://doi.org/10.15232/aas.2019-01896.

Stahel, P., J. P. Cant, J. A. MacPherson, H. Berends, and M. A. Steele. 2016. A mechanistic model of intermittent gastric emptying and glucose-insulin dynamics following a meal containing milk components. PLoS One 11:e0156443. https://doi.org/10.1371/ journal.pone.0156443.

Storn, R., and K. Price. 1997. Differential evolution-A simple and efficient heuristic for global optimization over continuous spaces. J. Glob. Optim. 11:341-359. https://doi.org/10.1023/A: 1008202821328

Tikofsky, J. N., M. E. Van Amburgh, and D. A. Ross. 2001. Effect of varying carbohydrate and fat content of milk replacer on body composition of Holstein bull calves. J. Anim. Sci. 79:2260-2267. https://doi.org/10.2527/2001.7992260x.

Urie, N. J., J. E. Lombard, C. B. Shivley, C. A. Kopral, A. E. Adams, T. J. Earleywine, J. D. Olson, and F. B. Garry. 2018. Preweaned heifer management on US dairy operations: Part I. Descriptive characteristics of preweaned heifer raising practices. J. Dairy Sci. 101:9168-9184. https://doi.org/10.3168/jds.2017-14010.

Vara, E., O. Fernández-Martín, C. García, and J. Tamarit-Rodríguez. 1988. Palmitate dependence of insulin secretion, "de novo" phospholipid synthesis and $45 \mathrm{Ca} 2+$-turnover in glucose stimu- lated rat islets. Diabetologia 31:687-693. https://doi.org/10.1007/ BF00278753.

Vara, E., and J. Tamarit-Rodriguez. 1986. Glucose stimulation of insulin secretion in islets of fed and starved rats and its dependence on lipid metabolism. Metabolism 35:266-271. https://doi.org/10 .1016/0026-0495(86)90212-X.

Vicari, T., J. J. G. C. van den Borne, W. J. J. Gerrits, Y. Zbinden, and J. W. Blum. 2008. Postprandial blood hormone and metabolite concentrations influenced by feeding frequency and feeding level in veal calves. Domest. Anim. Endocrinol. 34:74-88. https://doi.org/ 10.1016/j.domaniend.2006.11.002.

Wijayasinghe, M. S., N. E. Smith, and R. L. Baldwin. 1984. Growth, health, and blood glucose concentrations of calves fed high-glucose or high-fat milk replacers. J. Dairy Sci. 67:2949-2956. https://doi .org/10.3168/jds.S0022-0302(84)81658-6.

Yang, Y. J., J. H. Youn, and R. N. Bergman. 1987. Modified protocols improve insulin sensitivity estimation using the minimal model. Am. J. Physiol. 253:E595-E602. https://doi.org/10.1152/ajpendo .1987.253.6.E595.

\section{ORCIDS}

A. C. Welboren () https://orcid.org/0000-0003-1403-2954

B. Hatew @ (ttps://orcid.org/0000-0002-7235-716X

O. López-Campos @ https://orcid.org/0000-0002-2346-0451

J. P. Cant () https://orcid.org/0000-0003-2021-1764

L. N. Leal $\odot$ https://orcid.org/0000-0002-7798-3995

J. Martín-Tereso (으 https://orcid.org/0000-0002-6757-4629

M. A. Steele @ https://orcid.org/0000-0001-6941-6205 